\title{
Citizen Science as Democratic Innovation That Renews Environmental Monitoring and Assessment for the Sustainable Development Goals in Rural Areas
}

\author{
Cristian Alarcon Ferrari ${ }^{1, *}{ }^{1}$, Mari Jönsson ${ }^{2} \mathbb{D}$, Solomon Gebreyohannis Gebrehiwot ${ }^{3}$,

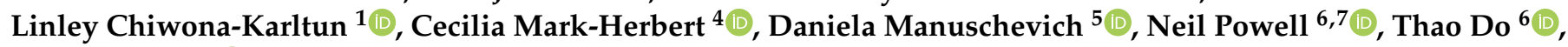 \\ Kevin Bishop ${ }^{8}\left(\mathbb{D}\right.$ and Tuija Hilding-Rydevik ${ }^{9}$
}

check for updates

Citation: Alarcon Ferrari, C.; Jönsson, M.; Gebreyohannis Gebrehiwot, S.; Chiwona-Karltun, L.; Mark-Herbert, C.; Manuschevich, D.; Powell, N.; Do, T.; Bishop, K.; Hilding-Rydevik, T. Citizen Science as Democratic Innovation That Renews Environmental Monitoring and Assessment for the Sustainable Development Goals in Rural Areas. Sustainability 2021, 13, 2762. https:// doi.org/10.3390/su13052762

Academic Editor: Jordi Colomer Feliu

Received: 31 October 2020

Accepted: 18 February 2021

Published: 4 March 2021

Publisher's Note: MDPI stays neutral with regard to jurisdictional claims in published maps and institutional affiliations.

Copyright: (c) 2021 by the authors. Licensee MDPI, Basel, Switzerland. This article is an open access article distributed under the terms and conditions of the Creative Commons Attribution (CC BY) license (https:/ / creativecommons.org/licenses/by/ $4.0 /)$.
1 Department of Urban and Rural Development, Swedish University of Agricultural Sciences (SLU), 75007 Uppsala, Sweden; linley.chiwona.karltun@slu.se

2 Swedish Species Information Centre, Swedish University of Agricultural Sciences (SLU), 75007 Uppsala, Sweden; mari.jonsson@slu.se

3 Ethiopian Institute of Water Resources, Addis Ababa University, 15046 Addis Ababa, Ethiopia; solomon358.sg@gmail.com

4 Department of Forest Economics, Swedish University of Agricultural Sciences (SLU), 75007 Uppsala, Sweden; cecilia.mark-herbert@slu.se

5 Department of Geography, University of Chile, 8331051 Santiago, Chile; danielamanuschevich@uchile.cl

6 Sustainability Learning and Research Centre (SWEDESD), Uppsala University, 75237 Uppsala, Sweden; neil.powell@swedesd.uu.se (N.P.); thao.do@swedesd.uu.se (T.D.)

7 Sustainability Research Centre, University of the Sunshine Coast (USC), 4558 Queensland, Australia

8 Department of Aquatic Sciences and Assessment, Swedish University of Agricultural Sciences (SLU), 75007 Uppsala, Sweden; kevin.bishop@slu.se

9 Swedish Biodiversity Center, Swedish University of Agricultural Sciences (SLU), 75007 Uppsala, Sweden; tuija.hilding-rydevik@slu.se

* Correspondence: cristian-alarcon.ferrari@slu.se

Abstract: This commentary focuses on analyzing the potential of citizen science to address legitimacy issues in the knowledge base used to guide transformative governance in the context of the United Nation's Sustainable Development Goals (henceforth SDGs). The commentary develops two interrelated arguments for better understanding the limits of what we term "traditional" Environmental Monitoring and Assessment (EMA) as well as the potential of citizen science (CS) for strengthening the legitimacy of EMA in the local implementation of SDGs. We start by arguing that there is an urgent need for a profound renewal of traditional EMA to better implement the SDGs. Then, we present CS as a democratic innovation that provides a path to EMA renewal that incorporates, develops, and extends the role of CS in data production and use by EMA. The commentary substantiates such arguments based on current approaches to CS and traditional EMA. From this starting point, we theorize the potential of CS as a democratic innovation that can repurpose EMA as a tool for the implementation of the SDGs. With a focus on the implementation of SDG15 (Life on Land) in local contexts, the commentary presents CS as a democratic innovation for legitimate transformative governance that can affect socio-ecological transitions. We see this approach as especially appropriate to analyze the implementation of SDGs in rural settings where a specific resource nexus can create conflict-laden contexts with much potential for a renewed EMA to support transformative governance towards Agenda 2030.

Keywords: citizen science; democratic innovation; Environmental Monitoring and Assessment; Sustainable Development Goals; forests; legitimacy; transformative governance

\section{Introduction}

Agenda 2030 implies a clear mandate for rapid social-ecological transformations at national levels [1]. However, its success depends to a great degree on the social legitimacy 
of the knowledge base used to guide transformative governance toward the realization of the United Nation's Sustainable Development Goals (henceforth SDGs) in rural local areas. Thus, the national level of analysis for the implementation of SDGs depends on local environmental governance where the interrelated nature of the SDGs and the challenges of resource allocation require socio-ecological analysis to navigate toward a sustainable future. Within this context, rural areas play a key role in the achievement of SDGs, but rural communities are often forced to make trade-offs between the environment and economic development [2]. Environmental Monitoring and Assessment (henceforth EMA) has been a customary way to do this, but it is predicated on centralized, expert solutions that may lack legitimacy with local actors. This raises crucial questions concerning the current role and the future of EMA in contributing with legitimate knowledge to the realization of Agenda 2030 as well as its specific goals and targets in rural settings.

Citizen science (henceforth CS) is touted as a data source that can provide new knowledge for the achievement of the SDGs [3]. In doing so, the participatory nature of citizen science can potentially contribute to a renewal of EMA. This could foster the acceleration and scaling up of initiatives to better address the societal challenges of the SDGs in rural areas, including taking advantage of advances in technology and the proliferation of data for the development of CS. Here, citizen science has the potential to renew EMA by promoting public engagement horizontally in the co-production of knowledge (e.g., volunteering with local data and knowledge) as well as vertically, in decision-making (e.g., engaging with government organizations in consultations and decision-making). Yet this requires institutional reforms aimed at rethinking EMA for transformative governance to allow public engagement in sustainable and democratic transitions to become a key driver for the achievement of the SDGs in local areas. Such normative goals need more empirical analysis regarding the possibilities for CS to renew EMA as a tool to support the achievement of SDGs. However, attention also needs to be paid to the barriers facing the use of CS for this purpose.

One especially challenging implementation of SDGs in rural settings relates to competing objectives for the use of forest resources. This leads to questions about the very meaning of SDG15 ("protect, restore and promote sustainable use of terrestrial ecosystems, sustainably manage forests, combat desertification, and halt and reverse land degradation and halt biodiversity loss") given the potential for conflicts between economic development, the livelihoods of people, and biodiversity. This compromises the prospects for achieving this SDG in ways that are widely accepted as legitimate processes of environmental governance, thus jeopardizing the prospects for transformative environmental governance.

The purpose of this commentary is to lay out a theoretical framework for analyzing why and how citizen science can contribute to EMA in order to enable legitimate transformative governance connected to SDG15 in rural areas. We argue that a potential path for EMA renewal is to incorporate and extend the relevance of CS in EMA. We present this as a democratic innovation in the production of data and knowledge for the SDGs. We see this as an important step toward the empowered participatory governance of natural resources in rural settings. Thus, this commentary argues for a profound renewal of traditional Environmental Monitoring and Assessment (EMA) to promote implementation of the SDGs. In connection with this, we argue that citizen science should be conceived of as a democratic innovation that provides a path to the renewal of Environmental Monitoring and Assessment. This involves incorporating, developing, and institutionalizing the role of citizen science in data and knowledge production to provide decision support about sustainable use of natural resources in rural areas.

This commentary is divided into two sections. The first section offers an analysis of social and natural science approaches to citizen science within existing forms of Environmental Monitoring and Assessment. This is the starting point for theorizing the potential of citizen science as a democratic innovation that can repurpose EMA as a tool for the implementation of the SDGs. The second section theorizes citizen science as democratic 
innovation for legitimate transformative governance and socio-ecological transitions in rural areas. Here, we focus especially on the implementation of SDG15.

\section{Traditional Environmental Monitoring and Assessment Needs Citizen Science and Participatory Processes to Be Relevant for Agenda 2030 and the SDGs}

The involvement of non-scientists in the citizen-based production of knowledge and management of data has been addressed frequently in science and policy. This has been promoted as an innovative form of participation in the democratization of science $[4,5]$. Today, it is recognized that citizen science projects not only serve to achieve scientific objectives, but they can also realize significant social outcomes [6]. CS initiatives show that there is a clear interest in different societal actors being involved in the scientific process, from acting as observers and data collectors, to working on assessments with practitioners, planners, and evaluators. Varied approaches of public engagement and knowledge production in science, crowdsourcing, and community science have come together under the umbrella of CS [7-9]. Even if the majority of CS projects do not lead to scientific publication [10,11], they significantly contribute to the science-societypolicy interface through enhancing public awareness and empowerment. Many different definitions can be found for CS, but at least three forms of CS can be identified [12]:

1. Citizen science as a research method, aiming for credible scientific output.

2. Citizen science as public engagement, aiming to establish legitimacy for science and science policy in societal decision-making.

3. Citizen science as civic engagement collecting and using data aiming for legal or political influence in relation to specific issues.

The three forms of CS identified by O'Rourke and Macey [13] designate somewhat different ways of performing citizen science. This includes contributing as helpers to the sciences (the first form), contributing as actors seeking knowledge and representation in decision-making processes (the second form), as well as a hybrid, borrowing traits from both forms (the third form) in order to reach goals on specific issues initiated by members of local communities. The first two approaches cover a range of different levels of participation that suit a broader range of societal actors. The participatory and public dimension of the knowledge produced in CS is of relevance to Environmental Monitoring and Assessment in the implementation of SDGs in terms of (i) encouraging citizens to participate in the EMA process by observing, gathering, and processing data as well as (ii) co-designing ways forward for EMA and progress toward SDGs. The latter includes evaluating two-way learning outcomes through participatory processes. Merging these socio-ecological formats for engaging with various societal actors may enhance the democratic dimensions of current citizen science innovation into updated and reformulated EMA frameworks. Indeed, it was highlighted at the first European Citizen Science Association (ECSA) conference in 2016 that to enhance innovation in science, CS needs to clearly demonstrate its scientific benefit, branch out across disciplines, and foster active networking and new formats of collaboration, including true co-design and co-production of knowledge with participants [14].

However, CS is about participation in data production for environmental management and despite valuable insights into CS in the context of implementing SDGs, important governance challenges persist concerning how to fully integrate CS into established EMA frameworks. First, a compelling framework integrating CS into EMA for SDGs implementation remains elusive. Secondly, there is still a need for empirical comparisons focused on the potential for (as well as barriers to) CS in areas where there are conflicts and synergies between SDGs. This is especially relevant in rural settings characterized by a resource nexus with formal legal arrangements for resource control. In this context, CS can even serve to rethink the role of existing environmental laws and regulation. As Overdevest and Mayer [15] argue: "The next generation of environmental law can realize a more cost effective, richer base of information about environmental quality by creatively drawing on resources from civil society at the same time that it encourages a more active citizenry". 
Addressing this point is crucial when thinking how citizen science can help transform Environmental Monitoring and Assessment in settings where environmental regulation is mainly done through different forms of legal regulation. Yet, a caveat is important in this context: scaling up the use of CS to the legal and normative level of environmental governance implies that the institutions involved in this kind of governance need to have public procedures to deal with data gaps and the voluntary nature of CS as well. This resonates with Conrad and Hilchey [16], who note that more knowledge is needed on the barriers for the incorporation of CS data into official assessments and policy decisions. Thus, the power of data collected by citizens needs to be analyzed in political terms, too. This raises fundamental issues concerning the political processes that mediate the production of data and knowledge through CS and how the results of CS could be scaled up into local policy making.

Such issues cannot be separated from the different scales in which those political processes are immersed, since local governance initiatives are part of wider structures of political decision-making. This is clearly observable when considering the role of municipalities in environmental planning and their potential to foster CS in innovative new forms of EMA. A report founded by the European Union (EU) on CS in so-called smart cities concluded that CS projects raise awareness, build capacity, and strengthen communities. However, that study also found that "to date there seems to be little synergy between citizen science and smart cities initiatives, and there is little interoperability and reusability of the data, apps, and services developed in each project" [17]. This gap between CS potential and the integration of data into local policy and regulation is even more challenging in rural areas where municipalities often lack resources to produce data relevant to the local resource nexus and environmental objectives that are of direct, everyday interest for livelihoods in rural communities. Thus, an important potential of citizen science to improve wider environmental policy resides precisely in providing usable local knowledge for a resource nexus approach to the Sustainable Development Goals [18].

As Bleischwitz et al. [19] state, a resource nexus is a "set of context-specific critical interlinkages between two or more natural resources used in delivery chains towards systems of provision for water, energy, food, land and materials". Within this context, one of the SDGs that is of fundamental importance for several other goals in rural areas is SDG15, which mandates the following: "Protect, restore and promote sustainable use of terrestrial ecosystems, sustainably manage forests, combat desertification, and halt and reverse land degradation and halt biodiversity loss". In analyzing this SDG in the light of a growing body of forest research in the social-ecological context, we note that forms of politics, forest, and land management play a crucial role in giving local meaning to sustainable management of forests and land. Furthermore, taking into consideration that forests and land are often in a resource nexus, we face important analytical challenges when addressing the political decisions on different resources implied in SDG15. Yet, Sayer et al. [20] note that, "... SDG15 could raise the profile of conservation within the broader community" but there is also a "tendency for SDG15 to be viewed as a second-tier goal behind the others" [20]. In addition, a sound conceptual and empirical analysis of both forest politics and policy is crucial in the creation of new knowledge in the context of the interlinkages between forestry, policy, and current sustainability challenges [21]. Such political and policy dimensions in the efforts to work with SDG15 in rural areas are often deeply interconnected with conceptions of EMA based on technocratic, professional, and expert-based top-down assumptions about data production for environmental management. Furthermore, in some contexts, there are no coherent and coordinated EMA systems that can adequately guide public environmental policy and decisions in relation to forest and land resources. Thus, the democratizing potential of CS in rural forest settings of SDG15 implementation needs to be analyzed with special attention to context-specific political factors interacting with different approaches to EMA and the local institutions within which EMA systems are defined. 


\section{Beyond Data Collection in Traditional Environmental Monitoring and Assessment: Citizen Science as Democratic Innovation in Rural Areas and the SDGs}

The analysis above indicates that there is clear recognition of the potential democratic relevance of scaling up citizen science for use in institutions supporting the implementation of Agenda 2030. This points toward thinking about how particular CS initiatives can fit in a more comprehensive CS framework that makes CS an integral part of the institutional governance systems where EMA is currently used. Yet, more knowledge is needed concerning how to effectively integrate CS into EMA to facilitate transformative governance for social-ecological transitions. In addition, there is a gap between the growing, evolving, and technologically advanced CS knowledge and the existing formal political and policy structures of environmental governance $[22,23]$. This needs to be more deeply analyzed to understand how the knowledge base obtained through CS can foster legitimacy in local and national governance of resources. Incorporating CS into EMA is one way to do this, but there are political issues of fundamental importance when analyzing steps toward opportunities for CS in SDG-relevant EMA. The political issues that need more analysis range from rejection of CS knowledge by powerful actors to lack of incentives and support for wider public participation in CS.

To contribute to that analysis, we will conceive CS as a "democratic innovation" for public engagement [24]. This allows us to envision political paths that move beyond the current limits of CS in existing governance settings and promote the potential of CS to become a democratic innovation for involving citizens in EMA. This can give both citizen science as well as Environmental Monitoring and Assessment a stronger role in political decision-making processes surrounding Agenda 2030. We theorize citizen science as a democratic innovation for transformative governance and socio-ecological transitions under the premise that developing CS is often done in contexts characterized by democratic deficits in environmental governance. Our approach to CS in such terms draws from Smith's definition of democratic innovation which conceives this as "institutions that have been specifically designed to increase and deepen citizen participation in the political decision-making process" [25].

However, considering CS as an institution creates several conceptual problems and challenges. Three of these challenges are important to consider in relation to CS initiatives in contexts where forest and land resources are sources of economic activity and growth. First, there is the challenge of creating public recognition of CS data as legitimate inputs for reforming environmental governance that might impinge upon the interests of powerful local actors. Secondly, there is the problem of unequal access to technological tools for participating in CS that originate from economic differences. This can lead to new ways of marginalizing people in environmental governance processes. Thirdly, spatial and temporal bias can affect the trust in the validity of data produced through CS.

Despite these concerns, the definition of democratic innovations is still adequate as a starting point for giving CS broader levels of impact in EMA. One such impact is on the vertical dimension of public engagement, which involves influencing policy. Another impact could be on the horizontal dimension of public engagement, which builds governance capacity among the citizenry. Developing citizen science in this horizontal dimension involves participation within existing local governance structures for environmental decision making, as far as EMA is a feature of those structures. Here, the local transformations that CS could bring about in EMA can be seen in terms of institutionalizing CS as a new way of fostering public participation in governance. In so doing, CS is generally about not only increasing and deepening public participation, but it is a specific way to empower citizens in the production of decision support inputs to local governance and decision-making.

In this context, augmenting EMA with CS could be driven by external reporting requirements. However, that is more about trying to "prove" that existing governance systems work, rather than enhancing the ability of governance processes to change existing situations that fall short of the ambitions of Agenda 2030. We argue that a "conserving" view of EMA where CS just meets formal expectations of public participation does not 
address the need for transformative decision-making based on data and assessments that have quality, are accessible, and timely for supporting the implementation of the SDGs.

Citizen science in EMA must be treated as a necessary step toward what has been understood in terms of empowered participatory governance [26]. This arises from the potential of CS as a democratic innovation transforming institutions where empowered participatory governance means reliance on the participation and capacities of ordinary people in reason-based decision-making through action and discussion [26]. We argue that this is crucial for new sources of legitimacy in the implementation of SDG15 in rural settings where "traditional" EMA is based on professional systems. These systems involve centrally organized data collection where the results are placed in the hands of experts with a monopoly on interpreting these data.

Taking into account that our analysis of the potential of CS as a democratic innovation for EMA in rural settings will focus on contexts where there are political structures for formal democracy, we complement our definitions of democratic innovation and empowered participatory governance with some theoretical insights into legitimacy. Bernstein's understanding of legitimacy, which has been widely referred to in literature on environmental governance, states that:

"Legitimacy can be defined as the acceptance and justification of shared rule by a community. This definition self-consciously combines an empirical measure of legitimacy (acceptance of a rule or institution as authoritative) and a normative argument concerning whether the authority possesses legitimacy (providing reasons that justify it)".

As has been observed, the international nature of the SDGs raise a number of legitimacy problems [28], and we can add here that traditional EMA, with its assumptions about experts and top-down data production for environmental governance, is not well equipped to offer the sort of data revolution for the SDGs envisioned in Agenda 2030. Thus, a deeper understanding of legitimacy issues concerning interactions between CS, EMA, and SDGs is needed. This should take into consideration the actors and procedures involved in sustainability questions. To more deeply analyze such issues, Bäckstrand's distinction between input and output legitimacy is useful:

"Input legitimacy concerns whether the process conforms to procedural demands, such as representation of relevant stakeholders, transparency and accountability. Output legitimacy revolves around effectiveness or 'problem solving capacity' of the governance system. In the context of partnerships for sustainable development, legitimacy is captured in the following two questions. Do private-public partnerships 'perform' and 'deliver' the promised results-based environmental governance? Are partnerships open to public scrutiny and representative and inclusive of different stakeholders' interests?".

Input and output legitimacy resonates in Bexell's analysis of legitimacy in the global context of the SDGs, which distinguishes between legitimacy that "resides in perceptions about appropriate rule among those who are formally subject to a political institution or otherwise affected by its policies" [30] and political legitimacy, which "means that the exercise of political authority lives up to a standard of appropriateness theoretically defined by the scholar" [30]. As Bexell notes, input legitimacy is linked to procedural and democratic sources of legitimacy, and output legitimacy is linked to effective problemsolving sources of legitimacy [30].

We draw on those insights on the distinction between input and output legitimacy to analytically distinguish and evaluate the role of CS as a democratic innovation to renew EMA. First, such a conceptual distinction makes it possible to evaluate processes and outcomes involving CS. Secondly, it allows for identifying the structural barriers that CS encounters in the process of incorporating new knowledge toward social-ecological transformations in different institutional settings. Furthermore, clear criteria for legitimacy enhances the ability to problematize issues surrounding power relationships in the use of 
CS and EMA when evaluating progress toward the achievement of SDGs in local contexts. In this regard, distinguishing between input and output legitimacy focuses our analyses on the role of data production and use involving CS when evaluating case studies on the implementation of SDGs.

In this regard, strengthening the environmental planning tools of rural municipalities and the provision of enough resources for developing and institutionalizing local citizen science appear as potentially important steps to overcoming barriers in the way of a further development of citizen science in rural areas. Crucially, this should take into consideration institutional reforms to allow more empowered participatory governance by marginalized rural people in the local decisions on resources. In principle, this could help empower both rural inhabitants and municipalities in areas with growing power asymmetries concerning data production on water, forest, and land resources. However, as we have emphasized earlier, this all depends on contingent political processes. Therefore, we have called attention to the importance of explicitly considering the politics of citizen science in any effort to further develop CS for a renewal of Environmental Monitoring and Assessment aiming at participatory forms of transformative environmental governance.

Finally, we would like to share a reflection on how our approach to EMA is, to an important degree, based on some lessons from research on EMA and implementation of SDGs in different national contexts in Sweden and Chile during the past two years. These cases, and their context-specificity, have given us valuable inputs and empirical perspectives for a critical approach to our own academic engagement in contributing to more democratic local environmental governance. A lesson learned from these cases is that much more attention to legitimacy issues is needed when rethinking EMA in the context of the SDGs in rural settings. In reflecting on this, our own normative expectations for more democratic forms of environmental governance become entangled in our analysis, as we firmly believe that the prospects of citizen science in providing new sources of legitimacy for environmental governance are worthy of being discussed in both academic and political terms.

In this regard, our critical reflection tells us that academic engagement in the politics of citizen science should not idealize CS. Furthermore, we should seek critical reflection on barriers to developing CS in settings where a professional approach to EMA is currently established. With this in mind, we see our call for a renewal EMA by incorporating CS as a normative goal that is connected to how academic experts in EMA think and act in relation to institutional changes. These institutional changes concern new norms, rules, understandings, and routines needed in environmental governance if the SDGs are to be achieved.

Thus, we situate ourselves as actors in the renewal of Environmental Monitoring and Assessment to account for power relations in knowledge production, as well as in understanding how the agency of local actors working with researchers in citizen science can foster the legitimacy of renewed EMA systems. If we argue that developing CS is key in socio-ecological settings where actors make different claims to the use of resources, which is often the case in transitions to sustainable land/forest use, it is because we self-critically see our roles as researchers contributing to the vertical dimension of public engagement in environmental governance. This, we believe, needs to be fostered by developing new opportunities for the public to know what the status of the local environment is, and for embracing the need for changes in society in line with the SDGs at local levels.

\section{Conclusions}

This commentary has shown how theorizing citizen science as a democratic innovation provides a conceptual lens for analyzing the potential and barriers for citizen science in renewing Environmental Monitoring and Assessment (EMA) to better support the implementation of the Sustainable Development Goals (SDGs). We see this approach as particularly valuable in analyzing the implementation of SDGs in rural settings where the nexus surrounding different resources creates conflict-laden situations. In these contexts, 
EMA is expected to provide a legitimate evidence base to help navigate a path between SDG conflicts and synergies that leads to the achievement of Agenda 2030. Since legitimacy deficits are a fundamental problem in the implementation of the SDGs, we have connected the prospects of CS as a democratic innovation to the understanding of input and output legitimacy. This helps to capture the challenges of making inclusive participatory processes an integral feature in local decision-making about the allocation of human, economic, and environmental resources. We believe that these conceptual contributions open important paths for the practical improvement of data production and assessment, the democratization of science, and public participation that facilitates transformative local governance toward Agenda 2030 in rural contexts. The latter point about rural contexts is something easily missed when the focus is on Agenda 2030 at national scales.

Author Contributions: Individual contributions to this commentary were as follows: Conceptualization, C.A.F., M.J., S.G.G.; L.C.-K., C.M.-H., D.M., N.P., T.H.-R. and K.B.; Methodology, C.A.F., M.J. and D.M.; investigation, C.A.F., M.J. and D.M.; resources, C.A.F., M.J. and K.B., writing-original draft preparation, C.A.F.; writing—review and editing, C.A.F., M.J., L.C.-K., C.M.-H., D.M., N.P., T.D., T.H.-R. and K.B.; project administration, K.B.; funding acquisition, C.A.F., M.J. and K.B. All authors have read and agreed to the published version of the manuscript.

Funding: This research was funded by FORMAS, grant number 2018-02341.

Institutional Review Board Statement: Not applicable.

Informed Consent Statement: Not applicable.

Data Availability Statement: No new data were created or analyzed in this study. Data sharing is not applicable to this article.

Acknowledgments: The authors thank fellow project participant Torbjörn Ebenhard, for constructive discussions.

Conflicts of Interest: The authors declare no conflict of interest.

\section{References}

1. United Nations. Transforming Our World: The 2030 Agenda for Sustainable Development; United Nations: New York, NY, USA, 2015; p. 35.

2. OECD. Rural Well-Being: Geography of Opportunities; OECD: Paris, France, 2020.

3. Fritz, S.; See, L.; Carlson, T.; Haklay, M.; Oliver, J.L.; Fraisl, D.; Mondardini, R.; Brocklehurst, M.; Shanley, L.A.; Schade, S.; et al. Citizen science and the United Nations Sustainable Development Goals. Nat. Sustain. 2019, 2, 922-930. [CrossRef]

4. Holocher-Ertl, T.; Kieslinger, B. Green paper on Citizen Science for Europe: Towards a Society of Empowered Citizens and Enhanced Research; European Commission: Brussels, Belgium, 2013.

5. Pocock, M.J.O.; Chapman, D.S.; Sheppard, L.J.; Roy, H.E. Choosing and Using Citizen Science: A Guide to When and How to Use Citizen Science to Monitor Biodiversity and the Environment. Available online: http://nora.nerc.ac.uk/id/eprint/510644/ (accessed on 30 October 2020).

6. Bonney, R.; Shirk, J.L.; Phillips, T.B.; Wiggins, A.; Ballard, H.L.; Miller-Rushing, A.J.; Parrish, J.K. Next steps for citizen science. Science 2014, 343, 1436-1437. [CrossRef] [PubMed]

7. Bonney, R.; Cooper, C.B.; Dickinson, J.; Kelling, S.; Phillips, T.; Rosenberg, K.V.; Shirk, J. Citizen science: A developing tool for expanding science knowledge and scientific literacy. BioScience 2009, 59, 977-984. [CrossRef]

8. Shirk, J.L.; Ballard, H.L.; Wilderman, C.C.; Phillips, T.; Wiggins, A.; Jordan, R.; McCallie, E.; Minarchek, M.; Lewenstein, B.V.; Krasny, M.E.; et al. Public participation in scientific research: A framework for deliberate design. Ecol. Soc. 2012, 17, 17. [CrossRef]

9. Silvertown, J. A new dawn for citizen science. Trends Ecol. Evol. 2009, 24, 467-471. [CrossRef] [PubMed]

10. Kullenberg, C.; Kasperowski, D. What is citizen science?-A scientometric meta-analysis. PLoS ONE 2016, 11, e0147152. [CrossRef] [PubMed]

11. Theobald, E.J.; Ettinger, A.K.; Burgess, H.K.; DeBey, L.B.; Schmidt, N.R.; Froehlich, H.E.; Wagner, C.; HilleRisLambers, J.; Tewksbury, J.; Harsch, M.A.; et al. Global change and local solutions: Tapping the unrealized potential of citizen science for biodiversity research. Biol. Conserv. 2015, 181, 236-244. [CrossRef]

12. Kasperowski, D.; Kullenberg, C.; Mäkitalo, Å. Embedding Citizen Science in research: Forms of engagement, scientific output and values for science, policy and society. SocArXiv 2017. [CrossRef]

13. O'Rourke, D.; Macey, G.P. Community environmental policing: Assessing new strategies of public participation in environmental regulation. J. Policy Anal. Manag. 2003, 22, 383-414. [CrossRef] 
14. Hecker, S.; Bonney, R.; Haklay, M.; Hölker, F.; Hofer, H.; Goebel, C.; Gold, M.; Makuch, Z.; Ponti, M.; Richter, A.; et al. Innovation in citizen science-Perspectives on science-policy advances. Citiz. Sci. Theory Pract. 2018, 3, 4. [CrossRef]

15. Overdevest, C.; Mayer, B. Citizen science and the next generation of environmental law. Beyond Environ. Law Policy Propos. A Better Environ. Future 2010, 109-128. [CrossRef]

16. Conrad, C.C.; Hilchey, K.G. A review of citizen science and community-based environmental monitoring: Issues and opportunities. Environ. Monit. Assess. 2011, 176, 273-291. [CrossRef] [PubMed]

17. Craglia, M.; Granell, C. Citizen Science and Smart Cities; EU SCIENCE HUB: Ispra, Italy, 2014; p. 26652.

18. Fraisl, D.; Campbell, J.; See, L.; Wehn, U.; Wardlaw, J.; Gold, M.; Moorthy, I.; Arias, R.; Piera, J.; Oliver, J.L.; et al. Mapping citizen science contributions to the UN sustainable development goals. Sustain. Sci. 2020, 15, 1735-1751. [CrossRef]

19. Bleischwitz, R.; Spataru, C.; VanDeveer, S.D.; Obersteiner, M.; van der Voet, E.; Johnson, C.; Andrews-Speed, P.; Boersma, T.; Hoff, H.; van Vuuren, D.P. Resource nexus perspectives towards the United Nations Sustainable Development Goals. Nat. Sustain. 2018, 1, 737-743. [CrossRef]

20. Sayer, J.; Sheil, D.; Galloway, G.; Riggs, R.A.; Mewett, G.; MacDicken, K.G.; Arts, B.; Boedhihartono, A.K.; Langston, J.; Edwards, D.P. SDG 15: Life on Land-The Central Role of Forests in Sustainable Development. In Sustainable Development Goals: Their Impacts on Forests and People; Cambridge University Press: Cambridge, UK, 2019.

21. Alarcón, C.F.; Hansen, H.P. Forest research from a critical perspective-How can it contribute to new knowledge? Scand. J. For. Res. 2012, 27, 108-119. [CrossRef]

22. Mazumdar, S.; Ceccaroni, L.; Piera, J.; Hölker, F.; Berre, A.; Arlinghaus, R.; Bowser, A. Citizen science technologies and new opportunities for participation. In Citizen Science-Innovation in Open Science, Society and Policy; Hecker, S., Haklay, M., Bowser, A., Makuch, Z., Vogel, J., Bonn, A., Eds.; UCL Press: London, UK, 2018; pp. 303-320.

23. Sauermann, H.; Vohland, K.; Antoniou, V.; Balázs, B.; Göbel, C.; Karatzas, K.; Mooney, P.; Perelló, J.; Ponti, M.; Samson, R.; et al. Citizen science and sustainability transitions. Res. Policy 2020, 49, 103978. [CrossRef]

24. Mejlgaard, N.; Bloch, C.; Degn, L.; Nielsen, M.W.; Ravn, T. Locating science in society across Europe: Clusters and consequences. Sci. Public Policy 2012, 39, 741-750. [CrossRef]

25. Smith, G. Democratic Innovations: Designing Institutions for Citizen Participation; Cambridge University Press: Cambridge, UK, 2009; ISBN 978-1-139-47970-7.

26. Fung, A.; Wright, E.O. Deepening democracy: Innovations in empowered participatory governance. Politics Soc. 2016, 29, 5-41. [CrossRef]

27. Bernstein, S. Legitimacy in global environmental governance. Int. J. Comp. Labour Law Ind. Relat. 2004, 1, 139.

28. Katila, P.; Colfer, C.J.P.; de Jong, W.; Galloway, G.; Pacheco, P.; Winkel, G. Sustainable Development Goals; Cambridge University Press: Cambridge, UK, 2019; ISBN 978-1-108-48699-6.

29. Bäckstrand, K. Multi-stakeholder partnerships for sustainable development: Rethinking legitimacy, accountability and effectiveness. Eur. Environ. 2006, 16, 290-306. [CrossRef]

30. Bexell, M. Routledge Handbook of Global Sustainability Governance; Kalfagianni, A., Fuchs, D., Hayden, A., Eds.; Routledge: Abingdon-on-Thames, UK, 2019; ISBN 978-1-351-69129-1. 